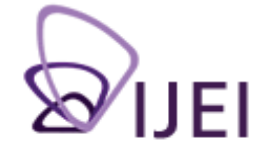

International Journal for Educational Integrity

\title{
'Another chance to practice': Repeating plagiarism education for EAL students within a discipline context
}

\author{
Sue McGowan \\ School of Commerce \\ University of South Australia \\ Margaret Lightbody \\ School of Commerce \\ University of Adelaide
}

Keywords: plagiarism, accounting, EAL students

\begin{abstract}
The accounting and education literatures contain many expressions of concern regarding the perception that plagiarism is on the rise and, particularly, the challenges for English as an Additional Language (EAL) students in mastering the academic referencing requirements underpinning Western-based university programs. This paper outlines an assignment specifically developed to assist EAL students in a second-year financial accounting course delivered in Hong Kong, to develop an understanding of plagiarism issues within the context of their study discipline. The analysis of results indicates that the assignment was effective in enhancing students' understanding of referencing and plagiarism, and confirms the need to actively repeat plagiarism education throughout a study program. The assignment was also seen to have enhanced the quality of students' written work, arguably due to the nature of the assignment as closely replicating the learning methodologies familiar to the Hong Kong student cohort.
\end{abstract}

\section{Introduction}

The perception that plagiarism is on the rise in universities is a topic dominating academia (see, for example, Brimble \& Stevenson-Clarke, 2005; de Lambert, Ellen \& Taylor, 2006; Marshall \& Garry, 2006; Park, 2003) and the media (see, for example, Barthel, 2007). While plagiarism can be perceived as dishonest or unethical behaviour, it can also result from "honest confusion" (Wilhoit, 1994, p. 161) regarding appropriate academic referencing conventions (Edwards \& Ran, 2006; Park, 2003; Shi, 2004). Much has been written in the academic literature advocating the importance of, first, giving students an understanding of the nature of plagiarism and the penalities imposed on transgressors and, second, teaching students to reference correctly to avoid plagiarism. In response, most universities have policies outlining the nature of plagiarism and the penalties associated with its use. Many also provide communication courses or other materials designed to ensure students are aware of accepted referencing practices.

Despite the efforts of universities, a common problem identified in numerous studies appears to be that whilst most students are aware of the issues many do not know, or choose to ignore, how to put referencing conventions into practice (Allan, Gallagher,

The International Journal for Educational Integrity is available online at

http://www.ojs.unisa.edu.au/journals/index.php/IJEI/

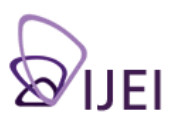


Connors, Joyce \& Rees, 2005; Brimble \& Stevenson-Clarke, 2005; de Lambert, Ellen \& Taylor, 2006; McGowan, 2005; Scanlan, 2003; Wilhoit, 1994). It thus appears that current approaches to providing plagiarism education materials may be insufficient to instil either the knowledge or the willingness to avoid plagiarism.

While plagiarism is perceived as a growing problem for all student cohorts, studies have found that students for whom English is an additional language are more likely to engage in behaviour labelled 'plagiarism' than their first language counterparts (Deckert, 1993; Marshall \& Garry, 2006; Pecorari, 2003; Shi, 2004). Factors seen to contribute to greater rates of plagiarism amongst EAL students include their developing English language skills (Bretag, Horrocks \& Smith, 2002; Introna, Hayes, Blair \& Wood, 2003; Lahur, 2004; McGowan, 2005; Pecorari, 2003; Shi, 2004), differing cultural norms regarding textual borrowing (Introna, Hayes \& Blair, 2003; Lahur, 2004; Pennycock, 1994, 1996), and pressures to succeed (Edwards \& Ran, 2006; Introna et al., 2003; Lahur, 2004; Marshall \& Garry, 2006). While the latter driver is to a large degree outside the influence of an individual academic, universities attempt to address the former two factors by providing opportunities for students to learn correct referencing.

Coming to terms with the various forms of behaviours perceived as plagiarism is a complex process for all students, regardless of background. This may be particularly challenging for EAL students from educational backgrounds that emphasise reproduction of text materials as a demonstration of knowledge (Chan, 1999; Edwards \& Ran, 2006; Introna et al., 2003; Lee, 1996) and for students who may have "less well-developed study skills (including note taking, essay writing and bibliography construction skills)" (Park, 2003, p. 480). Merely threatening punishment for failure to comply with referencing requirements may be an insufficient learning mechanism for students and may result in students being "held responsible for a standard they clearly do not grasp" (Deckert, 1993, p. 142). Rather, students appear to require "an improved understanding of how to engage in academic writing" (Marshall \& Garry, 2006, p. 34) in terms of their understanding of how to appropriately reference the materials they use.

Commentaries on teaching additional-language students frequently reinforce the need for such students to be given both the time and support to develop their academic writing and their referencing skills (Edwards \& Ran, 2006: Introna et al., 2003). In particular, there is a need for Western academic standards to be made explicit. Edwards and Ran $(2006$, p. 8) suggest that "if you can take [Chinese students] through [referencing] step by step and show them exactly how it is done and then keep getting them to practice, that works...rather than expecting them to be able to do it or find out for themselves". Likewise, assignments will be more beneficial to students' learning when they are structured so students perceive "their assessments as an opportunity to learn" (Hayes \& Introna, 2005b, p. 229) rather than a potential for punishment if they fail to appropriately reference. The structure of Western disciplinebased programs that enrol EAL students thus need to provide additional mechanisms that support the explicit teaching of referencing skills so EAL students can develop effective academic writing skills.

This paper considers a multifaceted process to educate Hong Kong students, enrolled in an Australian-based undergraduate accounting program, about plagiarism and referencing. In particular, the paper focuses on an assignment developed within a second-year undergraduate accounting course that was intended to build on prior plagiarism education provided to the student cohort. The paper is structured as follows: first, some background is provided in relation to the student cohort; second, the process to educate students about plagiarism and referencing is described; third, the results from analysis of student achievement and evaluations are discussed. Finally the implications of these findings and recommendations are summarised. 


\section{Background}

As part of their internationalisation strategy, many Australian universities deliver their Australian-based degree programs to student cohorts in Asia. This paper focuses on an Australian-based undergraduate accounting degree taught as part of a 'twinning arrangement' with a Hong Kong university. The content of the Hong Kong accounting program and each of its component courses was identical to that of the Australian program. However, teaching arrangements in Hong Kong differed from those in Australia. While the students were provided with extensive written materials and Internet-based support from Australian academics, in Hong Kong, face-to-face lectures were delivered by Australian academics who travelled to Hong Kong twice a semester to present materials in an intensive mode over four days. Tutorials were undertaken by Hong Kong-based tutors with direction from Australian teaching staff. All assessment marking was undertaken by Australian academic staff.

Virtually all of the Hong Kong students worked full-time and studied part-time. Most entered the accounting program with credit for either six courses (a quarter of the undergraduate degree) or eight courses (one third of the degree) from a vocational higher certificate or diploma in accountancy from a Hong Kong education institution. This prior learning enabled the majority of students to meet the English language proficiency entrance requirements of the program.

In 2003, changes were implemented to address the increasing instances of plagiarism by Hong Kong students and the rising concerns about the general level of academic writing skills of students. In particular, staff felt concerned that the students may not have had sufficient knowledge of what constituted plagiarism and how to avoid it. Prior to 2003, the advice formally provided by the University to the majority of Hong Kong accounting students about plagiarism, referencing and academic writing was limited to that provided at university orientation sessions that all new students were required to attend when first commencing their university program. The accounting program included a full first-year Communications course where these topics were covered. However, the majority of accounting students did not undertake it as they had received credit for the course. To remedy this perceived deficiency the University decided that students commencing in 2003 would not be given credit for the Communications course. Instead, all students (subject to transitional arrangements) were required to undertake a new Business Communication Skills course (BCS). This new course was based on a similar course designed and taught in Australia specifically for EAL students. Students were also required, where feasible, to take this course as early as possible in the program.

The first three topics of BCS covered academic conventions including extensive information on plagiarism and referencing. The first assignment, weighted at $15 \%$, required each student to correct a poorly planned and referenced essay. The specific instances of plagiarism in this essay were clearly identified for students, although referencing was incomplete. Students were precluded from continuing in the course if this assignment was not passed.

Because of concerns that students needed additional tuition regarding plagiarism and referencing, an emphasis was to be continued into the second-year financial accounting course. In previous semesters, there had been unacceptably high levels of plagiarism by students doing the essay assignment in this course. Academics were concerned that students may not carry through the knowledge of plagiarism learned in previous generic courses to discipline specific contexts. There was thus seen to be benefits for accounting students of having plagiarism re-emphasised in their discipline context. Hence in the revised accounting program, plagiarism and referencing were addressed in a coordinated approach via three delivery mechanisms: first, student orientation sessions and materials; second, a specific communications course tailored to the students; and third, reinforcement within a second-year accounting course. 


\section{Plagiarism assignment}

While the co-ordinated approach required second-year students to emphasise ethical behaviour, to be effective the course required formal assessment beyond a 'mere' plagiarism exercise. Academics have noted that the majority of students are strategic learners who direct their efforts at the materials being assessed (Ramsden, 1992; Logan \& Hazel, 1999; Zhang \& Watkins, 2001). This is particularly so for part-time students, often with limited time for their studies. Likewise, studies also show that students perceive material as more relevant if presented within a core discipline topic (Drury, 1999; Elander, 2003). If the assignment incorporated a consideration of plagiarism within a financial accounting topic, this would emphasise the relevance of plagiarism within the discipline context. Further, while the plagiarism assignment replaced existing financial accounting assignments, to keep workloads manageable, the assignment needed to also provide coverage of core course content and learning objectives.

The following assessment item (weighted at 20\%) was introduced into the secondyear financial accounting course. The assignment required students to undertake three tasks:

1. Complete an online workshop (no marks awarded but students were required to sign a declaration that this was completed).

2. Correctly reference a 925-word pre-written essay, along with the related reference list (graded out of a maximum of ten marks).

3. Write a 500-word conclusion on an accounting issue (graded out of a maximum of ten marks).

The first task ensured all students understood the issues relating to plagiarism and referencing and that they could locate resources related to referencing prior to undertaking the assignment.

The core component was a 'plagiarised' essay prepared by the lecturer. This essay presented a number of alternative views on a financial accounting topic, using a range of given articles but without including the necessary in-text citations. The 2004 essay was based on seven readings from various sources including professional websites, online journals and reports, newspapers and academic journals. Where possible, access to these readings was via a web link as this replicated how students often locate references. Web-based materials were used, as research indicates that a common form of plagiarism is the practice of 'cutting and pasting' material from web sites into essays (Baruchson-Arbib \& Yaari, 2004; Introna et al., 2003; Marshall \& Garry, 2006). Students were informed that the pre-written essay had ten instances of plagiarism. To complete the assessment, students needed to read the essay and readings to identify the instances of plagiarism and to correctly reference them. Students were not told the nature or the location of the errors. However, where the readings were large, students were directed to a limited range of pages. This approach, as well as testing referencing techniques, also demonstrated to students the ease of identifying plagiarism within an essay.

The essay incorporated various types of plagiarism to give students experience and practice correcting typical mistakes. The instances of plagiarism included:

- $\quad$ Six quotations. Two were changed, but not sufficiently to be considered a paraphrase; many students incorrectly believe a slight change, addition, or deletion constitutes a paraphrase.

- Two paraphrases because students often believe that unless material is directly quoted, no citation is required. 
- $\quad$ One quote of a quote within a reading because students often reference original sources rather than the material accessed.

- One citation relating to the use of ideas/research.

The final component required students to draw on arguments in the text and materials to develop a 500-word conclusion to the essay. To attain a passing grade, this conclusion had to be justified by a consideration of alternative arguments, and be correctly and completely referenced. The conclusion was graded for the quality of the arguments and while no marks were allocated for correct referencing, any instances of plagiarism or incorrect referencing were penalised.

\section{Outcomes}

The outcomes of the assignment were measured in two ways: first, by student grades in the assignment, and secondly, by a survey to obtain student evaluations of the assignment. At the conclusion of the course, students were surveyed: first, to ascertain whether they felt the assignment impacted on their understanding of plagiarism and referencing, and secondly, if the integration of the plagiarism exercise with a discipline specific learning task had benefits for their understanding of the accounting issue. The survey sought both quantitative and qualitative feedback, asking first, to answer a number of 'tick the box' questions and, second, providing the opportunity to write comments. The evaluation instrument was distributed during a lecture prior to the exam. This limited potential respondents to students attending that lecture. The evaluations were anonymous and voluntary. Of the 123 students in the course, 79 completed the evaluation, a response rate of $64 \%$.

\section{Results of the plagiarism assignment}

In $2004,89 \%$ of students passed this assignment with an average grade of $69 \%$. The average for the plagiarism task was $77 \%$ with $11 \%$ failing. This indicated that most students' understanding of referencing was very good. For students' own conclusion to the essay, the average mark was $62 \%$, with $13 \%$ failing. There were also no instances of plagiarism detected in the students' own conclusions or the subsequent assignment in the course. This compared favourably with the essay assignment in the same course in 2003, where 30 students were penalised for plagiarism in the form of 'cutting and pasting'.

\section{The impact of the assignment on students' understanding of plagiarism}

The survey asked students to categorise, as poor, average or good, their level of understanding of plagiarism and referencing before and after the assignment (see Table 1). 
Table 1, Students' evaluation of their understanding of plagiarism

\begin{tabular}{|c|c|c|c|c|c|c|c|}
\hline & \multicolumn{3}{|c|}{ BEFORE } & \multicolumn{3}{|c|}{ AFTER } & \multirow{3}{*}{$\begin{array}{l}\text { Percent } \\
\text { with } \\
\text { increased } \\
\text { knowledge } \\
\text { a }\end{array}$} \\
\hline & \multirow{2}{*}{$\begin{array}{l}\text { Poor } \\
\%\end{array}$} & \multicolumn{2}{|c|}{ AverageGood } & \multirow{2}{*}{$\begin{array}{l}\text { Poor } \\
\%\end{array}$} & \multicolumn{2}{|c|}{ Average Good } & \\
\hline & & $\%$ & $\%$ & & $\%$ & $\%$ & \\
\hline Knowledge of what 'plagiarism' is & 29 & 51 & 20 & 0 & 65 & 35 & $42^{b}$ \\
\hline $\begin{array}{l}\text { Knowledge/understanding of the } \\
\text { penalties imposed on students if they } \\
\text { are found guilty of plagiarism. }\end{array}$ & 16 & 58 & 26 & 4 & 47 & 49 & $37^{b}$ \\
\hline $\begin{array}{l}\text { Understanding of when it is necessary } \\
\text { to include in-text references. }\end{array}$ & 36 & 48 & 16 & 9 & 43 & 48 & $54^{b}$ \\
\hline $\begin{array}{l}\text { Understanding of how to correctly cite } \\
\text { in text references used (ie using the } \\
\text { Harvard/author date system of } \\
\text { referencing). }\end{array}$ & 36 & 48 & 16 & 8 & 48 & 44 & $55^{b}$ \\
\hline $\begin{array}{l}\text { Knowledge of where to find } \\
\text { information about how to reference } \\
\text { correctly (ie from the Learning } \\
\text { Connection web site). }\end{array}$ & 30 & 58 & 12 & 8 & 48 & 44 & $54^{b}$ \\
\hline & & & & & & & YES\% \\
\hline $\begin{array}{l}\text { Overall, do you think the plagiarism as } \\
\text { improving your knowledge and unders } \\
\text { information used in an assignment? }\end{array}$ & $\begin{array}{l}\text { ssignn } \\
\text { standir }\end{array}$ & & $\begin{array}{l}\text { useful } \\
\text { /how to }\end{array}$ & earnin & & & 74 \\
\hline
\end{tabular}

\footnotetext{
a This indicates students moving from either 'poor' to 'average' or 'good', and from 'average' to 'good'.

${ }^{\mathrm{b}}$ Non-parametric goodness of fit tests indicate that the changes in ratings are significant at the $0.001 \%$ level.
}

Overall, students reported their understanding of plagiarism and referencing was enhanced, with $74 \%$ agreeing that the assignment had improved their knowledge and understanding of how and when to correctly reference. A significant percentage of students reported that prior to undertaking the assignment their understanding of referencing and plagiarism was poor. Likewise, relatively few students reported that they felt their understanding of what plagiarism was good $(20 \%)$ or that they had a good knowledge of how and when to reference (16\%). Only $12 \%$ felt they had a good knowledge of where to find referencing information.

The evaluation instrument did not ask students to indicate whether they had undertaken BCS and no comparison is made on this basis. However, $71 \%$ of students had undertaken or were taking it concurrently with this course. The level of students that did not indicate a good knowledge of plagiarism and referencing prior to this assignment indicates that further reinforcement of plagiarism and referencing beyond BCS is required. While it could be expected that students' knowledge of how to cite materials may not be rated as good (because of inherent intricacies and specifics of referencing), it would still be expected that their level of knowledge of what constitutes plagiarism and when to reference would be higher. Interestingly, a coordinator of the BCS course has stated that they felt any student who successfully completed BCS in Hong Kong could not possibly make the argument they did not understand plagiarism and referencing. Yet the majority of students rated their prior knowledge as less than good. 
After completing the assignment, $42 \%$ of students reported greater levels of knowledge of plagiarism and over $50 \%$ indicated greater confidence with referencing. All students reported at least an average knowledge of plagiarism, with $35 \%$ perceiving their knowledge as good. Likewise, the majority of students felt they had an average knowledge of when and how to reference; almost half were confident they had a good knowledge of referencing. Students also reported increased knowledge of where to find information about how to reference. They reported a greater appreciation of the importance of referencing in academic settings. Further, $74 \%$ felt the plagiarism assignment was a useful tool for improving their knowledge of when and how to reference.

A large proportion of students provided written comments in the survey. The majority of comments to the question concerning the usefulness of the assignment for learning referencing conventions were positive and gave insights into the factors influencing such usefulness. Many students commented that the assignment gave them a further opportunity to practice referencing, thus improving their understanding of the requirements introduced in previous communications courses.

...we learned this from BCS before, but we just do one or two assignments only. We can have more chance to practice it.

I was studying plagiarism in the previous course, I already knew how to reference, but not the detail. After this assignment, I learnt more and clearly. This assignment is good practice for students to understand the topic.

It reminded me of what I learnt in the course BCS.

Many students felt being made to work through a practical exercise of identifying instances of plagiarism and having to correct the referencing was more effective than simply providing information and expecting students to apply it to their work.

It is easy to find the plagiarism information from course website and information booklet. But we never read them carefully or word by word until we have got an assignment on it.

Have practice rather than theory.

However, not all feedback was supportive. Students who did not feel the assignment was useful argued they had learned how to reference in BCS and such material need not be repeated in accounting.

Waste of my time because I have already learnt it [referencing] in BCS course.

Some students argued that knowledge of referencing was not part of accounting and should be located in non-accounting courses.

Those requirements for plagiarism...it is not related to the specific knowledge of Financial Accounting.

While students had mixed feelings regarding the need for the plagiarism assignment, the findings of this study suggest most students derived some benefit. In particular, this study supports previous literature that it is not sufficient to teach referencing in one generic first-year course (Willingham, 2003). Most students had completed studies of referencing prior to the plagiarism assignment. However, given around one 
third of students reported they had poor knowledge of referencing before the assignment there was a clear need for more opportunities to either re-learn or practice referencing. This need was supported by students' comments, with most emphasising the role of the plagiarism assignment as a reinforcement of, or a chance to practice, material introduced in BCS.

The benefits of teaching referencing in more than one course are supported by both education and second-language literature. There is a widespread acceptance that conventions of referencing are often complex and not always easy to apply (Park, 2003; Wilhoit, 1994). This is particularly so for EAL students with less developed English skills, who may have greater difficulty understanding what is required to correctly reference (Edwards \& Ran, 2006; Marshall \& Garry, 2006) or may use 'patch -writing' approaches to written work (Currie, 1998; Hu, 2001; Introna et al., 2003; Pecorari, 2003). The findings of this study indicate benefits for most students when referencing conventions are reinforced through formal exercises (Paxton, 2007), rather than assuming that referencing taught in a foundation course provides sufficient knowledge and confidence. In this way, students progressively develop adequate referencing skills (Edwards \& Ran, 2006; Introna et al., 2003; Paxton, 2007).

While the principles of repetition and reinforcement benefit students, providing them with explicit examples, rather than simply requiring them to correctly reference their work, may have particular merit for students from Chinese backgrounds. Chan (1999, p. 299) argues that two core characteristics of Chinese education are "emphasis on perception of the concrete" and "non-development of abstract thought". As previously noted, referencing is taught in Western universities by providing students with access to information about the rules to be applied in subsequent work. In this manner, students are expected to develop referencing skills from an abstract concept. Chan (1999) argues that Chinese education teaches children "through concrete examples" and that students find "areas... which require...abstract thinking [to be] difficult to grasp" (p. 299). Likewise Edwards and Ran (2006, p. 8) argue that Chinese students "are very good at learning and applying principles, but only after they have been made explicit" in their learning (Hu, 2001). By providing an essay in which the research material was incorporated, students had concrete or explicit examples of a wellstructured essay and its associated reading material on which to practice their referencing skills. The rules of referencing were firmly grounded in these examples, providing students with clear and unambiguous feedback regarding the material to be referenced and the manner in which to record material.

\section{The usefulness of the assignment for learning about an accounting issue}

In addition to asking about the impact of the assignment, the survey asked whether the exercise was effective for learning about an accounting issue. The majority of students $(74 \%)$ confirmed the assignment had 'helped [them] understand what is meant by the concept of true and fair and it's role in financial reporting'. The students identified three aspects that impacted on effectiveness.

First, the requirement to find the sources of plagiarism forced them to undertake close and repeated readings of the material. This in turn enhanced their understanding of the readings. Because I have to read through the essay many times in order to find out the
plagiarism part.

During the preparation for the assignment, always repeat reading. 
Second, the volume, quality, and range of the material meant they read more extensively than they might otherwise were they required to only identify relevant sources for themselves.

I need to read so many readings about true and fair.

Read more articles so understand more.

Lecturers viewed the two points above as having enhanced students' understanding of the accounting subject matter. However, some students felt the plagiarism exercise distracted from their learning about accounting.

When I prepare the assignment my focus is concerning the referencing so it can't really meet the requirements to let me understand true and fair.

I spent too much time to find out the plagiarism and forgot to jot down notes on what is 'true and fair' for the essay question.

The benefit of repeated readings identified by the students was unintended, but should have been expected as it replicates a learning method used by Chinese students. The literature identifies that Chinese learners use initial and repeated memorisation as an integral part of the process of understanding (Marton, Dall'Alba \& Tse, 1996) which is a core of Confucian learning traditions (Lee, 1996). Although this approach is viewed by some academics as rote learning, Watkins and Biggs (1996) sythesize a significant body of studies to argue that Chinese learners use a 'repetitive strategy' to develop a deep understanding of content (Biggs \& Watkins, 1996). The necessity to re-read the sources replicates a learning technique familiar to Hong Kong students and is a culturally appropriate learning methodology that enhances their knowledge of issues addressed in the materials.

Providing readings regarding the accounting issue was also seen to enhance students' understanding of the topic. Prima facie, the quality of any essay will be affected by the quality of the underlying research. Locating quality research requires time and skill. Anecdotally, academics lament that students often use the first six 'hits' in a Google search regardless of quality and often fail to recognise iterations of similar information. While identifying suitable research materials can be difficult for students, those with less-developed language proficiency find scanning potential sources more time-consuming and less effective because of difficulties interpreting the material (Edwards \& Ran, 2006; Gao, 1998; Introna et al., 2003). Students confirmed this point in the comments reported above. By ensuring the students' own essay writing included an appropriate range of research, the assignment facilitated consideration of more comprehensive positions and viewpoints, thus enhancing the students' understanding of the accounting issue. This contrasted with student essays in 2003, where a common cause of poor grades was a failure to consider a sufficient range of arguments or perspectives.

Providing the materials may also have benefited students' own research skills. The assignment acted as a model of the sources, type, and range of research required to appropriately write an essay (Deckert, 1993). Allowing students to observe an example of a well-researched essay in an accounting program may assist the development of research skills in terms of ability to apply them to the accounting discipline. This approach may again accidentally mirror a culturally appropriate method of teaching Hong Kong students. Chinese learning is grounded in respect for canonical texts (Chan, 1999: Lee, 1996). As noted above, a source of confusion and difficulty for students in conducting research is identifying authoritative texts (Introna et al., 2003). By locating a number of relevant articles, the lecturer identified canonical material, thus providing students with relevant material. Typically, it would be 
expected that a second-year university undergraduate could identify such material. However, students from non-Western backgrounds may need a greater period of their university studies in which to learn to seek out material (Edwards \& Ran, 2006; Paxton, 2007).

\section{The learning value of the plagiarism assignment compared with a traditional essay}

The student survey also asked whether students preferred the current style of assignment to one where they must research and write a full essay. Sixty-five percent of respondents indicated a preference for the current assignment, giving two main reasons. First, many felt the current assignment less demanding of their time. In particular, they noted the time constraints imposed by paid work.

It saves me much time doing research work where I found my time both studying and working a pain

If there's not provide the readings for us, it will waste more time to do the research but quite hard for the part time students

The second reason was that it eliminated the challenging task of locating supporting research for an essay.

Because 7 reading are quite large resources that provided both side of 'true and fair'... I cannot find the most relative information by myself

Need to study a lot of papers but may not be useful to the assignment

While the majority of students indicated a preference for the current format of assignment, $35 \%$ indicated they preferred a full essay to the current assignment. However, analysis of the comments indicated that, in many cases, preference was for a calculative assignment rather than an essay of any form.

I prefer the assignment format is accounting calculations

Not good at English, prefer calculations

A small number of students indicating a preference for a full essay suggested such an assignment would develop their writing and research skills.

Because we can read more easily from outside, and improve our writing skills

Makes students more clearly understand how to do better work for later courses.

The feedback from students indicating a preference for the new assignment was not surprising. As noted, EAL students often experience difficulties in identifying and synthesizing materials due to their developing English language skills and education background. The time required by such exercises was deemed an onerous imposition as they were all working while studying and had less time to devote to their studies than full-time students. While impossible to identify individual students providing written comments, it is reasonable to suppose the students who indicated a preference for a full essay were probably students with more advanced English language skills. 


\section{Unexpected benefits}

While the assignment contributed to an improvement in students' understandings of referencing and plagiarism, a significant and unexpected improvement occurred in the quality of students' 500-word conclusion compared with the 'full' essays submitted in the course in 2003. In particular, the higher grades were attributed to an absence of plagiarism, better incorporation of argument, and less cut-and-paste techniques in writing opinion compared to summary. Factors influencing these observations are discussed below.

First, no plagiarism was found in any student conclusion. This could be attributed to the enhanced understanding of plagiarism and referencing. Another possible reason is student expectations of the likely detection of plagiarism (Introna et al., 2003). As students had just completed an exercise in plagiarism, they may well have expected the lecturer to look for plagiarism in the written conclusion. Further, the nature of the assignment effectively shifted students' perspective from writer to reviewer, potentially making them aware of how easily plagiarism is detected.

Second, when compared to essays prepared in 2003, the 2004 conclusions demonstrated improved incorporation of arguments regarding accounting issues. Developing written arguments that use the voices of other authors is known to present difficulties for EAL students. While this problem is partially due to their developing English language skills, a number of authors note that students, when educated in disciplines or environments emphasising the textbook as primary reading, tend to have limited experience with the process of incorporating others' voices into their writing (Introna et al., 2003; Lahur, 2004; Paxton, 2007). Paxton (2007, p. 110) argues that the "monologic nature" of textbook writing means they present "the multitude of past, contesting voices... as a single voice" rather than demonstrating "the ways in which academic writers weave their own voices through a multiplicity of other acknowledged voices" in formal written academic discourse. Likewise, textbooks often borrow or synthesise ideas without acknowledgement or attribution of their source. Consequently, students relying on such writing are not provided with examples of how to incorporate or acknowledge these voices in their writing. As much accounting education relies on textbooks and many students came from educational backgrounds that place an emphasis on the text, it is reasonable to assume that many of the students had had limited exposure to other models of academic writing. A pre-written essay incorporating research materials may have supplied students with "models of academic argument [from which] they learnt how to draw on evidence from different sources to support an argument and how to position themselves in relation to other authoritative voices" (Paxton, p. 112). An understanding gained from explicit examples of how to place voices in a text may have caused some improvement in student essays.

The third source of improvement may be production of opinion rather than the summary-and-opinion required in traditional essays. While the full essay requires an opinion in its conclusion, the bulk of the essay would be comprised of a summary of alternative views. Shi (2004) found "much more textual borrowing" or copying from source texts in summary tasks than in opinion tasks as the tasks vary in terms of their "dependence on source information" (p. 190). Such 'patch-writing' is widely acknowledged as a logical strategy utilised by EAL students in response to the "linguistic challenge to summarise others' ideas in one's own words" (Shi, 2004, p. 182; Hu, 2001; Introna et al., 2003; Pecorari, 2003). Combined with EAL students' tendency to not reference patch-writing (Shi, 2004) summary tasks will result in higher incidences of plagiarism and lower grades because students 'cut-and-paste' rather than synthesise. Hence moving from a full essay to opinion piece may cause an improvement of marks because the focus is on the component that EAL students are more likely to write in their own words, rather than using patch-writing techniques. 


\section{Conclusion}

This paper presented and evaluated a multifaceted process to educate Hong Kong accounting students about plagiarism and referencing while enrolled in an Australian undergraduate program. A core feature of this process was the use of an integrated active-based learning assignment within a core second-year accounting course. The assignment was intended to build on previous plagiarism and referencing education through a process of development and support of students' learning processes, rather than a traditional framework of "detection and discipline" common in the advanced years of Western undergraduate programs (Hayes \& Introna, 2005a, p. 70). While the assignment results and feedback from the students showed that the assignment was successful in achieving its goals, a number of unexpected benefits were derived from the exercise.

Overall, the findings of the study support the need to re-teach material regarding plagiarism and referencing during an undergraduate program. While many of the student cohort were taught referencing within a first year communications course, they felt their knowledge of plagiarism and referencing was not good. As knowledge of such concepts is expected (and examined) in a modern Western university, such concepts need to be re-taught. There was also considerable benefit for EAL students in presenting materials regarding referencing and plagiarism within an explicit example or exercise, rather than requiring students to apply abstract concepts.

The plagiarism assignment was intended to improve students' knowledge of plagiarism and referencing. However, by inadvertently mirroring and incorporating learning techniques preferred by students from a Chinese educational background, the assignment developed academic research and writing skills more generally. By removing the need to conduct and synthesise research, the assignment took away the most difficult part of the writing process for EAL students, allowing them to focus on the process of learning to identify written voices. The nature of the pre-written component also appeared to provide examples of appropriate incorporation and referencing, thus giving students a model of writing to follow. Finally the repetitive reading required by the task enabled students to use a familiar learning methodology to enhance their discipline-specific knowledge.

The plagiarism assignment, as a discipline-based reinforcement, appeared successful. However, there were some limitations to the study. Much of the evaluation relied on student feedback which was possibly biased by personal perceptions (e.g. that the assignment should have improved their understanding of referencing). While the feedback suggested their knowledge of referencing had improved, no follow-up was performed to identify rates of plagiarism in subsequent cohorts of students. However, considerable evidence suggests that repeated and explicit plagiarism learning exercise can enhance EAL students' understanding of referencing and enable them to avoid accusations of plagiarism that result from "honest confusion" (Wilhoit, 1994) about appropriate Western academic writing standards. Likewise, utilising culturally familiar learning methods when teaching EAL students Western referencing conventions may also facilitate better outcomes for students, including a reduction in plagiarism itself.

\section{Acknowledgement}

The authors would like to thank Jeff Smith and Paul Burger for their assistance with the preparation of the paper and to acknowledge the helpful comments of the two anonymous reviewers. 


\section{Endnotes}

${ }^{1}$ For students studying part time, the financial accounting course would normally be in their $4^{\text {th }}$ or $5^{\text {th }}$ semester.

${ }^{2}$ The concept of the essay was derived from an assignment used in a first-year physiotherapy course at the university.

${ }^{3}$ In 2004 this issue was whether or not a company should be required to always follow accounting standards or whether they should be allowed to depart from these to provide a true and fair view.

${ }^{4}$ Students were directed to an electronic copy of the essay to insert appropriate referencing.

${ }^{5}$ Students were advised prior to participation that the results may be used for publication purposes.

${ }^{6}$ Note that a limitation of this assignment is that it would be difficult to identify plagiarism in the form of collusion in the correction of the pre-written essay.

${ }^{7}$ In 2004, the average mark for students' own conclusion to the essay was $62 \%$, with $13 \%$ failing. In 2003 , the average grade for the essay was $53 \%$, with $32 \%$ failing.

${ }^{8}$ However, anecdotal evidence from the coordinator of the subsequent financial accounting course showed rates of detected plagiarism for this cohort of students were much lower than in the previous year.

\section{Author Biographies}

Sue McGowan is a Senior Lecturer at the University of South Australia. She teaches in financial accounting with research interests in accounting education and internationalisation. Margaret Lightbody is a Senior Lecturer at the University of Adelaide and teaches in management accounting.

\section{References}

Allan, G., Callagher, L., Connors, M., Joyce, D., \& Rees, M. (2005). Some Australasian perspectives on academic integrity in the internet age. EDUCAUSE Conference, Auckland 2005. Retrieved February 15, 2007, from www.copyright.mq.edu.au/pdf/austperspect.pdf.

Baruchson-Arbib, S., \& Yaari, E. (2004). Printed versus internet plagiarism: A study of students' perceptions. International Journal of Information Ethics, 1, 1-6.

Barthel, A. (2007, October 10). Lost for words among the tight fists, The Australian. Retrieved October 23, 2007, from www.theaustralian.news.com.au/ story/0,25197,22558952-27702.html.

Biggs, J., \& Watkins, D. (1996). The Chinese learner in retrospect. In D. Watkins \& J. Biggs (Eds.), The Chinese learner: Cultural, psychological and contextual influences. Comparative Education Research Centre: Hong Kong and The Australian Council for Educational Research Ltd: Melbourne, 269-285.

Bretag, T., Horrocks, S., \& Smith, J. (2002). Developing classroom practices to support NESB students in Information Systems courses: Some preliminary findings. International Education Journal, 3(4). http://www.flinders.edu.au/ education/iej

Brimble, M., \& Stevenson-Clarke, P. (2005). Perceptions of the prevalence and seriousness of academic dishonesty in Australian universities. The Australian Educational Researcher, 32(3), 19-44.

Chan, S. (1999). The Chinese learner - A question of style, Education + Training, 41 (6/7), 294-304.

Currie, P. (1998). Staying out of trouble: Apparent plagiarism and academic survival, Journal of Second Language Writing, 7(1), 1-18.

Deckert, G. (1993). Perspectives on plagiarism from EAL students in Hong Kong. Journal of Second Language Writing, 2(2), 131-148. 
De Lambert, K., Ellen, N., \& Taylor, L. (2006). Chalkface challenges: A study of academic dishonesty amongst students in New Zealand tertiary institutions. Assessment \& Evaluation in Higher Education, 31(5), 485-503.

Drury, H. (1999). Providing the discipline context for skills development: Report on the production of an interactive video for oral and visual communication in the biological sciences. Paper presented at the HERDSA Annual International Conference, Melbourne, 12-15 July.

Edwards, V., \& Ran, A. (2006). Meeting the needs of Chinese students in British higher education. The University of Reading. Retrieved November 6, 2007, from http://ncll.org.uk/10 about/50 research/10 research projects/ MeetingTheNeeds.pdf.

Elander, J. (2003). A discipline-based undergraduate skills module. Pyschology Learning and Teaching, 3(1), 48-55.

Gao, M. (1998). Influence of native culture and language on intercultural communication: the case of PRC student immigrants in Australia. Paper presented at the Symposium of Intercultural Communication, Gothenberg University. Retrieved November 12, 2007, from http://www.immi.se/intercultural/ nr4/gao.htm.

Hayes, N., \& Introna, L. (2005a). Systems for the production of plagiarists? The implications arising from the use of plagiarism detection systems in UK universities for Asian learners. Journal of Academic Ethics, 3, 55-73.

Hayes, N., \& Introna, L. (2005b). Cultural values, plagiarism, and fairness: When plagiarism gets in the way of learning. Ethics \& Behaviour, 15(3), 213-231.

$\mathrm{Hu}, \mathrm{J}$. (2001). An alternative perspective of language re-use: Insights from textual and learning theories and L2 academic writing. English Quarterly, 33(1/2),52-59.

Introna, L., Hayes, N., Blair, L., \& Wood, E (2003). Cultural attitudes towards plagiarism: Developing a better understanding of the needs of students from diverse cultural backgrounds relating to issues of plagiarism. August, Lancaster University. Retrieved November 6, 2007, from http://www.jiscpas.ac.uk/images/ bin/lancplagiarismreport.pdf

Lahur, A. (2004). Plagiarism among Asian students at an Australian university offshore campus: Is it a cultural issue? A pilot study. Paper presented at HERDSA Conference, Malaysia. Retrieved February 15, 2007, from http:// herdsa2004.curtin.edu.my/contributions/NRPapers/A033-it.pdf

Lee, W. O. (1996). The cultural context for Chinese learners: Conceptions of learning in the Confucian tradition, In D Watkins \& J. Biggs (eds.), The Chinese Learner: Cultural, Psychological and Contextual Influences. Comparative Education Research Centre: Hong Kong and The Australian Council for Educational Research Ltd: Melbourne, 25-41.

Logan, P., \& Hazel, E. (1999). Language background and assessment in physical sciences. Assessment and Evaluation in Higher Education, 24(1), 53-65.

Marshall, S. \& Garry, M. (2006). NESB and ESB students' attitudes and perceptions of plagiarism. International Journal for Educational Integrity, 2(1), 26-37.

Marton, F., Dall'Alba, G., \& Tse, L. K. (1996). Memorizing and understanding: the keys to the paradox?, In D. Watkins \& J. Biggs (Eds.), The Chinese Learner: Cultural, Psychological and Contextual Influences. Comparative Education Research Centre: Hong Kong and The Australian Council for Educational Research Ltd: Melbourne, 69-83.

McGowan, U. (2005). Academic integrity: An awareness and development issue for students and staff. Journal for University Teaching and Learning Practices, 2 (3a). Retrieved February 15, 2007, from www.jutlp.uow.edu.au/2005 v02 i03a/ mcgowan005.html.

Park, C. (2003). In other (people's) words: Plagiarism by university students Literature and lessons, Assessment and Evaluation in Higher Education, 28(5), 471-488. 
Paxton, M. (2007). Tensions between textbook pedagogy and the literacy practices of the disciplinary community: A study of writing in first year economics. Journal of English for Academic Purposes, 6, 109-125.

Pecorari, D. (2003). Good and original: Plagiarism and patchwriting in academic second-language writing. Journal of Second Language Writing, 12, 317-345.

Pennycook, A. (1994). The complex contexts of plagiarism: A reply to Deckert. Journal of Second Language Writing, 3(3), 277-284.

Pennycook, A. (1996). Borrowing others' words: Text, ownership, memory, and plagiarism. TESOL Quarterly, 30(2), Summer, 201-230.

Ramsden, P. (1992). Learning to Teach in Higher Education, Routledge, London.

Scanlon, P. (2003). Student online plagiarism: How do we respond? College Teaching, 51(4), 161-165.

Shi, L. (2004). Textual borrowing in second-language writing, Written Communication, 21(2), 171-200.

Watkins, D., \& Biggs, J. (1996). The Chinese Learner: Cultural, Psychological and Contextual Influences, Comparative Education Research Centre: Hong Kong and The Australian Council for Educational Research Ltd: Melbourne.

Wilhoit, S. (1994). Helping students avoid plagiarism. College Teaching, 42(4), 161164.

Willingham, D. (2003). Why students think they understand - when they don't. American Educator, Winter. Retrieved December 5, 2007, from www.aft.org/ pubs-reports/american_educator/spring2004/cogsci.html.

Zhang, L., \& Watkins, D. (2001). Cognitive development and student approaches to learning: An investigation of Perry's theory with Chinese and US university students. Higher Education, 41(3), 239-261. 